\title{
PÓSTER 16
}

\section{EFECTOS DE LA DISFUNCIÓN DE LA ARTICULACIÓN TEMPOROMANDIBULAR SOBRE EL HABLA}

AUTORES: INSTITUCIÓN: PAIS:
Parra R.D, Angulo L.H. Equipo De Investigación De La Motricidad Orofacial Latinoamericana Lima-Perú

\section{RESUMEN}

Objetivo: El trabajo tuvo por objetivo identificar las características fonoarticulatorias de los individuos con disfunción temporomandibular (DTM), se consideró el tipo de alteración intraarticular envuelta, bien como verificar la influencia de las alteraciones oclusales sobre el habla. Materiales y Métodos: Para el estudio, fueron evaluados 46 personas adultas, de ambos sexos, de los cuales 16 constituyeron el grupo control y estando sin señales y síntomas de DTM. EI grupo de personas fue compuesto por 30 individuos que se encontraban en tratamiento de una DTM. Todos fueron sometidos a la evaluación fonoaudiológica para el análisis de la producción fonoarticulatoria y odontológica que evaluó los aspectos oclusales y articulares. Resultados: Los resultados obtenidos muestran que las alteraciones del habla en individuos con DTM son caracterizadas por desvíos anteriores (60\%) o laterales de la mandíbula (55\%), alteraciones en la inteligibilidad del habla (40\%) y proyección anterior de la lengua (15\%) durante la producción de los fonemas linguodentales. Conclusión: De los resultados, es posible sugerir, a partir del grupo investigado, que las alteraciones en el habla de personas con DTM son asociadas a las adaptaciones funcionales necesarias a las relaciones dento oclusales, musculares y articulares que presentan los mencionados individuos.

Palabras clave: Articulación Temporomandibular, Habla 